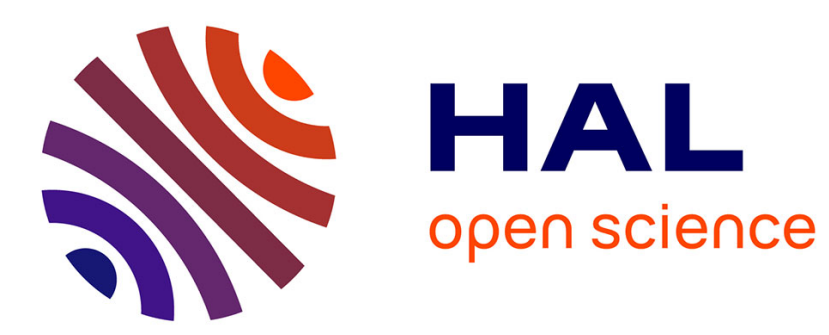

\title{
Cultural Proximity and Trade
}

Gabriel Felbermayr, Farid Toubal

\section{To cite this version:}

Gabriel Felbermayr, Farid Toubal. Cultural Proximity and Trade. European Economic Review, 2010, 54, pp.279-293. 10.1016/j.euroecorev.2009.06.009 . halshs-00641280

\section{HAL Id: halshs-00641280 https://shs.hal.science/halshs-00641280}

Submitted on 15 Nov 2011

HAL is a multi-disciplinary open access archive for the deposit and dissemination of scientific research documents, whether they are published or not. The documents may come from teaching and research institutions in France or abroad, or from public or private research centers.
L'archive ouverte pluridisciplinaire HAL, est destinée au dépôt et à la diffusion de documents scientifiques de niveau recherche, publiés ou non, émanant des établissements d'enseignement et de recherche français ou étrangers, des laboratoires publics ou privés. 


\title{
Cultural Proximity and Trade*
}

\author{
Gabriel J. Felbermayr ${ }^{\mathrm{a}}$ and Farid Toubal ${ }^{\mathrm{b}}$ \\ ${ }^{a}$ Department of Economics, University of Hohenheim, Germany \\ ${ }^{\mathrm{b}}$ University of Angers, Paris School of Economics and CEPII, France
}

\begin{abstract}
Cultural proximity is an important determinant of bilateral trade volumes. However, empirical quantification and testing are difficult due to the elusiveness of the concept and lack of observability. This paper draws on bilateral score data from the Eurovision Song Contest, a very popular pan-European television show, to construct a measure of cultural proximity which varies over time and within country pairs, and that correlates strongly with conventional indicators. Within the framework of a theory-grounded gravity model, we show that our measure positively affects trade volumes even if controlling for standard measures of cultural proximity and bilateral fixed effects.
\end{abstract}

JEL classification: F12, F15, Z10

Keywords: International Trade, Gravity Equation, Cultural Proximity, Eurovision Song Contest.

\footnotetext{
* We are grateful for comments and suggestions from two anonymous referees, from Philippe Aghion, Keith Head, Raquel Fernandez, Victor Ginsburgh, Kala Krishna, Philippe Martin, Thierry Mayer, Peter Neary, John Romalis, and from seminar participants at the universities of Zürich, WHU-Otto Beisheim School of Management, Paris School of Economics, the annual meetings of the Canadian Economic Association 2007 (Halifax), the EIIE 2007 (Ljubljana), the ETSG 2006 (Vienna) and the Verein für Socialpolitik 2006 (Bayreuth). We are very grateful to Jacques Melitz for providing us with his detailed data on language. Part of this research was undertaken while Felbermayr was visiting Zürich University. Benny Jung and Michael Böhm have provided excellent research assistance. The usual disclaimer applies.
} 


\section{Introduction}

There is wide-spread agreement that cultural proximity plays an important role in determining trade flows between countries. The literature has used different variables to proxy cultural ties, such as common language, religion, or ethnicity (Boisso and Ferrantino, 1997; Frankel, 1997; Melitz, 2008). ${ }^{1}$ While those variables clearly capture cultural proximity, they also reflect other tradecreating factors, such as the cost of communication.

In this paper, we exploit an original data set that contains information on cultural proximity between European countries. Each year in May, the European Broadcasting Union organizes the Eurovision Song Contest (ESC). This is a huge pan-European televised show, where every participating country sends an artist to perform a song. The other countries grade those songs, either by televoting, or (in earlier times) by popular juries. Every year, the process gives rise to a matrix of bilateral votes. Recent research shows that bilateral votes are strongly affected by conventional measures of cultural proximity, such as linguistic, ethnic, or religious ties (Ginsburgh and Noury, 2008; Ginsburgh, 2005; Clerides and Stengos, 2006). However, in contrast to standard indicators, the ESC scores vary over time and are potentially asymmetric.

ESC scores are informative about a broader concept of cultural proximity that is close to the definition used by sociologists (Straubhaar, 2002). Cultural proximity relates to the sharing of a common identity, to the feeling of belonging to the same group, and to the degree of affinity between two countries. The sociological concept allows for the evolution of bilateral attitudes and moods over time and for asymmetries within pairs of countries. A country's citizens can display respect and sympathy for the cultural, societal, and technological achievements of another country without this feeling necessarily being recip-

\footnotetext{
${ }^{1}$ Other recent examples include Alesina and Dollar (2000), who use cultural proximity measures in the context of explaining international aid, and Rose (2004), who studies the effect of WTO membership on trade. In Rauch and Trindade (2002) and Combes et al. (2005) cultural proximity is measured by the importance of ethnic ties across countries or regions. There is also a growing literature that correlates attitudes, sentiments, or customary beliefs to bilateral trade (Disdier and Mayer, 2005; Guiso, et al., 2004). Disdier et al. (2007) use bilateral trade in cultural goods as a proxy for cultural proximity.
} 
rocal and ever-lasting. Conventional measures of cultural proximity, such as common language, ethnicity, genetic traits, or religion are both time-invariant (pre-determined) and, by construction, symmetric and can therefore not fully capture the broad notion of cultural proximity.

Our interpretation of ESC scores is in line with anecdotal and systematic evidence on voting patterns across and within country pairs and over time. We show that some countries systematically award scores above average to each other and behave in a reciprocal way. We detect a Nordic, a Balkan, and a Mediterranean cluster. However, the observed degree of reciprocity can be low even between countries of seemingly similar cultural attributes, and the average degree of reciprocity is rather small.

Accounting for the unobserved quality of songs by including song-specific dummy variables, we discover a statistically significant and economically meaningful relation between bilateral ESC scores and the volume of trade between two countries. Looking at trade in differentiated goods, moving from the lowest to the highest degree of cultural proximity increases bilateral trade on average by $16 \%$ in our benchmark regressions. However, when considering trade in homogeneous goods, which are typically traded on organized exchanges, ESC scores are unrelated to bilateral trade volumes, signaling the irrelevance of cultural proximity for promoting trade in that category of goods. Interestingly, however, measures such as common language, common legal system, or ethnic ties do turn out statistically significant. Since there is little reason why cultural proximity should foster transactions taking place on anonymous organized exchanges, we take this finding as evidence that ESC scores strictly reflect cultural proximity while those other measures have more to do with other trade-promoting channels, such as the pure costs of translation or contracting.

The time-varying and asymmetric nature of ESC scores allows for a more elaborate econometric treatment. We can exploit the time dimension in order to deal with the potential endogeneity of grading behavior, to correct for nonsystematic measurement error in our index of cultural proximity or in order to control for time-invariant unobserved factors that drive both cultural prox- 
imity and bilateral trade. Following Baier and Bergstrand (2007), we include dyad-specific fixed effects to control for those initial conditions, thereby nudging our results nearer to the true causal effect of cultural proximity on trade. Our results suggest that cultural proximity increases bilateral trade by about $1.2 \%$ for differentiated goods, while, as before, it does not increase trade in goods transacted over organized exchanges. Using time lags as instruments, we find that OLS models also strongly underestimate the effect of cultural proximity on trade, probably due to the presence of measurement error. Hence, the central conclusion of our paper is that cultural proximity is a more important determinant of bilateral trade than researchers usually allow with the sort of cultural variables they include.

Our paper is related to different strands of the empirical gravity literature. We frame our analysis in a monopolistic competition trade model close to Combes et al. (2005), where an asymmetric weighting term in the utility function allows cultural proximity to affect preferences. The other channel through which cultural proximity matters is through trade costs. Our econometric setup follows Baldagi et al. (2003) and Baier and Bergstrand (2007), who include complete sets of interaction terms of importer/exporter dummies with year fixed effects into the gravity model. This strategy is a natural extension of the fixed effects approach discussed by Feenstra (2004). It appropriately controls for multilateral resistance (Anderson and van Wincoop, 2003) and other sorts of unobserved country-specific heterogeneity.

The received literature acknowledges the importance of the trade-cost and the preference channels; see Combes et al. (2005). However, that paper deals with migration and business networks; our exercise is related to a broader notion of cultural proximity. There are two interesting papers which show that distance captures more than transportation costs. Huang (2007) disentangles the distance effect of trade into a transport-cost and an unfamiliarity component. Blum and Goldfarb (2006) show that distance matters even for services that are entirely transacted over the internet and relate this finding to a preference effect. Our paper differs as it focuses on cultural proximity (not geographical distance), tries to explain patterns in trade in manufactures across Europe 
and pays due attention to endogeneity and identification concerns. ${ }^{2}$

The remainder of this paper is structured as follows. Section 2 provides a thorough discussion of the data and shows how one can use ESC scores to construct a meaningful measure of cultural proximity. Section 3 derives a generalized theoretical trade flow equation, which highlights the role of cultural proximity and which can be applied to bilateral data. Section 4 contains our core empirical results and shows how ESC scores are related to bilateral trade. Section 5 provides a number of extensions: it shows that our results are not driven by possible endogeneity of the ESC scores or unobserved heterogeneity. Section 6 concludes. Additional material and robustness checks can be found in our working paper as well as in a web appendix. ${ }^{3}$

\section{Eurovision Song Contest score data}

In this section, we discuss our data and show that the ESC scores are a meaningful measure of cultural proximity. We also discuss their statistical properties.

\subsection{The setup of the contest and measurement issues}

In 1955, a couple of European broadcasting stations represented in the European Broadcasting Union (EBU) founded the Eurovision Song Contest (ESC). A year later, the first contest took place in Lugano, Switzerland. The idea of the ESC is that each participating country selects an artist or a group of artists to perform a song, which is then graded by the other countries.

We focus on the period $1975-2003$, in which grading rules have been stable. ${ }^{4}$

\footnotetext{
2 There is also a growing literature on the relation between culture and economic outcomes; see Fernandez (2007) or Guiso et al. (2006) for comprehensive surveys, and Spolaore and Wacziarg (2009), Giuliano et al. (2006), Algan and Cahuc (2007) and Tabellini (2007) for interesting recent papers.

3 The web appendix can be downloaded from http://team.univ-paris1.fr/teamperso/toubal/papers/CP/CP.html.
} 
On average, from 1975 to 2003, 21.6 countries participated in the ESC, with the minimum participation being 18 countries. Contest participants are almost exclusively European countries. ${ }^{5}$ Each ESC is broadcast by television, and since 1985, this happens via satellite. In 2005, the contest was broadcast live in over 40 countries to over 100 million spectators. Until 1988, the scores were decided upon by a jury that is not necessarily consisting of experts. Nowadays, the scores are national averages obtained through a televoting process with huge popular participation. There are organizations of ESC fans in all EU countries.

Since 1975, each country scores the other countries' performances on a scale from 0 to 12 . The scores 9 and 11 are not allowed and 12 is the highest possible score. Each of the ten strictly positive grades has to be allocated exactly once; remaining countries are graded zero. The winner is the country that collects the largest sum of points.

We argue that ESC scores are broad indicators of cultural proximity. However, this interpretation poses one major difficulty, since the scores may reflect the quality of the song. Thus, we assume that country $i^{\prime} s$ support for country $j^{\prime} s$ performance at time $t, E S C_{i j t}$ depends positively on the quality of the song, $\zeta_{j t}$, on the degree of country $i^{\prime} s$ feeling of cultural proximity towards $j$ at time $t, \tilde{\Pi}_{i j t}$. In addition, the rules of the song contest disallow ties for the 10 most popular songs and force ties for the least popular ones. There is therefore no ordering of ESC scores below the top ten songs. Consequently, a separate dummy variable, $D_{i j t}$, is also appropriate for values of $E S C$ equal 0 when $D_{i j t}$ equal 1. Accordingly, $E S C_{i j t}=f\left(\tilde{\Pi}_{i j t}, \zeta_{j t}, D_{i j t}\right)$. Correspondingly we may say

$$
\tilde{\Pi}_{i j t}=f^{-1}\left(E S C_{i j t}, \zeta_{j t}, D_{i j t}\right) .
$$

$\tilde{\Pi}_{i j t}$ refers here to cultural proximity as it emerges from the song contest alone. We shall reserve the term $\Pi_{i j t}$ for cultural proximity based onother indicators as well.

\footnotetext{
${ }^{4}$ Until 2003, the last year in our sample, the contest was organized in a single round. From 2004 onwards, there are two rounds to accommodate the rising number of participants.

${ }_{5}$ Israel participates on a regular basis and Morocco has participated once. Both countries are not in our sample.
} 


\subsection{ESC scores as broad indicators of cultural proximity}

In this subsection, we show that ESC scores reflect time-invariant components of cultural proximity. We also argue that their time and within country-pair variance are in a meaningful way related to the broad definition of cultural proximity discussed in the introduction.

Ginsburgh (2005) shows that conventional measures of cultural proximity linguistic, ethnic, religious, political, etc. ties - determine ESC outcomes to a large extent, refuting the alternative hypothesis of vote trading (logrolling). Clerides and Stengos (2006) and Spierdijk and Vellekoop (2008) similarly document the importance of culture for scoring outcomes. Haan, Dijkstra, and Dijkstra (2005) test whether the transition of the grading process from jurybased voting to generalized televoting has strengthened the role of cultural proximity and answer this question in the affirmative. Fenn et al. (2006) run a cluster analysis and find evidence for unofficial cliques of countries along lines of cultural proximity. ${ }^{6}$

Table 1 shows pairwise correlation coefficients between raw and quality-adjusted ESC scores, on the one hand and conventional measures of cultural proximity $\Pi_{i j t}$ (excluded from $\tilde{\Pi}_{i j t}$ ) on the other. We have rescaled the ESC scores so that $E S C_{i j t} \in[0,1]$ to facilitate comparison with conventional measures of cultural proximity. ${ }^{7}$ The quality-adjusted ESC scores are the residuals from a regression of raw scores on song-dummies. We consider the following timeinvariant and symmetric measures of cultural proximity used in the literature: (i) an adjacency dummy and geographical distance between main cities (in kilometers); (ii) the Melitz (2008) measures of common language, namely; the continuous direct communication variable and the open-circuit communication dummy variable; ${ }^{8}$ (iii) a dummy for common legal origin borrowed from

\footnotetext{
6 See also Yair (1995) for an early study of that sort.

7 First, the original score of 10 is set to 9 and the score 12 is set to 10 . Then, we divide all scores by 10 . This rescaling does not affect our results.
} 
La Porta et al. (1999) ${ }^{9}$; (iv) a continuous religious proximity measure based on Alesina et al. (2000); (v) a measure of ethnic links based on the stock of individuals born in country $i$ but residing in country $j$; Appendix A provides information on the summary statistics of the variables, their exact definition and the data sources.

Table 1 Coefficients of correlation between different measures of cultural proximity

\begin{tabular}{lcc}
\hline & ESC score & Adjusted ESC score \\
\hline Adjusted ESC score & $0.8003^{* * *}$ & \\
Geographical distance & $-0.1918^{* * *}$ & $-0.2528^{* * *}$ \\
Adjacency & $0.1839^{* * *}$ & $0.2203^{* * *}$ \\
Direct communication & $0.1421^{* * *}$ & $0.1341^{* * *}$ \\
Open-circuit communication & $0.1633^{* * *}$ & $0.1861^{* * *}$ \\
Common legal origin & $0.1244^{* * *}$ & $0.2111^{* * *}$ \\
Religious proximity & $0.1317^{* * *}$ & $0.1669^{* * *}$ \\
Ethnic links & $0.3245^{* * *}$ & $0.1968^{* * *}$ \\
\hline 1 averaged across years. & \multicolumn{2}{l}{} \\
Number of observations: 901. *** denotes that coefficient is \\
different from zero at 1\% level of significance \\
\hline
\end{tabular}

The correlation between the quality adjusted ESC score and the raw ESC score data is 80.03. Hence, about a fifth of the variance in raw scores is accounted for by quality. The correlation coefficient between both ESC score measures and the conventional proxies of cultural and geographical proximity all have the right sign and are statistically different from zero. The adjusted ESC score displays larger correlation coefficients (with the exceptions of direct communication and ethnic links), signaling that quality adjustment improves our index of cultural proximity.

\footnotetext{
8 Melitz (2008) distinguishes whether ease of communication facilitates trade through translation or the ability to communicate directly (i.e., face-to-face). The first possibility is captured by the open circuit communication dummy, which takes value one if the language is either official or widely spoken (20\% of the population) in both countries (in any combination). The second possibility is captured by a direct communication measure which obtains by summing up the products of the respective percentages of speakers over all the relevant languages (at least $4 \%$ ) in the two trading countries.

9 Countries that once were part of the same larger political entity (such as, e.g., the Czech Republic and Hungary in the Austro-Hungarian Empire, England and Ireland, or Norway and Denmark) usually have the same legal system. Hence, that dummy also captures the broad institutional similarity of countries that have had a common past.
} 
Table 2

Explaining grading behavior

\begin{tabular}{|c|c|c|}
\hline & Poisson & $\begin{array}{l}\text { Zero } \\
\text { Inflated } \\
\text { Part }\end{array}$ \\
\hline Ln Distance & $\begin{array}{l}-0.150^{* * *} \\
(0.041)\end{array}$ & $\begin{array}{l}0.011 \\
(0.093)\end{array}$ \\
\hline Adjacency & $\begin{array}{l}-0.162^{*} \\
(0.087)\end{array}$ & $\begin{array}{l}0.010 \\
(0.207)\end{array}$ \\
\hline Both country in same FTA & $\begin{array}{l}-0.033 \\
(0.041)\end{array}$ & $\begin{array}{l}-0.038 \\
(0.092)\end{array}$ \\
\hline Direct communication & $\begin{array}{l}-0.230 \\
(0.145)\end{array}$ & $\begin{array}{l}-0.020 \\
(0.474)\end{array}$ \\
\hline Open-circuit communication & $\begin{array}{l}0.333^{*} \\
(0.191)\end{array}$ & $\begin{array}{l}-0.116 \\
(0.448)\end{array}$ \\
\hline Common legal origin & $\begin{array}{l}0.147^{* *} \\
(0.058)\end{array}$ & $\begin{array}{l}-0.004 \\
(0.129)\end{array}$ \\
\hline Religious proximity & $\begin{array}{l}0.248^{* *} \\
(0.101)\end{array}$ & $\begin{array}{l}0.032 \\
(0.211)\end{array}$ \\
\hline Ethnic ties & $\begin{array}{l}0.057^{* * *} \\
(0.017)\end{array}$ & $\begin{array}{l}0.024 \\
(0.019)\end{array}$ \\
\hline Observations & \multicolumn{2}{|c|}{10,560} \\
\hline Nonzero obs. & \multicolumn{2}{|c|}{5,135} \\
\hline Zero obs. & \multicolumn{2}{|c|}{5,425} \\
\hline McFadden's adjusted $R^{2}$ & \multicolumn{2}{|c|}{0.018} \\
\hline Log-Likelihood Full Model & \multicolumn{2}{|c|}{$-5,919.429$} \\
\hline Vuong Test: Zip vs. Standard Poisson & \multicolumn{2}{|c|}{$15.80^{* * *}$} \\
\hline $\begin{array}{l}\text { The regression contains song dummies } \\
\text { Standard errors (in brackets) have beer } \\
\text { around country pairs. } * * *, * * * \text { denote } \\
\text { the } 10,5 \text {, and } 1 \text { percent levels, respect }\end{array}$ & $\begin{array}{l}\text { and year } \\
\text { adjusted } f \\
\text { tatistical si } \\
\text { vely. }\end{array}$ & $\begin{array}{l}\text { xed effects. } \\
\text { clustering } \\
\text { aificance at }\end{array}$ \\
\hline
\end{tabular}

In Table 2, we present the results of a simple regression of ESC scores on various measures of cultural proximity. In order to account for song quality $\left(\zeta_{j t}\right)$ we include song dummies that are country-specific; moreover, the equation also contains year effects. Since we observe the same country pair over several years, we adjust the standard errors for clustering. ESC scores are count data censored at zero, so that it is natural to estimate a zero-inflated Poisson model. ${ }^{10}$ Indeed, the Vuong statistic indicates that this model has a better fit than the standard Poisson model. Interestingly, while all measures are strongly related to ESC scores in pairwise correlations, the multivariate

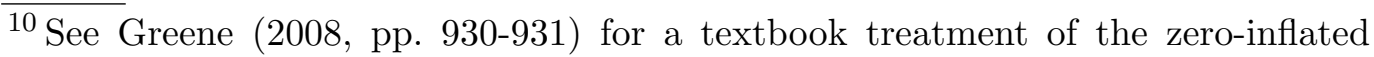
Poisson model and further references.
} 
analysis shows that direct communication does not matter for grading behavior. However, the other variables related to cultural proximity replicate the findings of table 1 . Note that none of the measures explains the zero-inflated part of the Poisson regression.

Table 3 shows that culturally close countries tend to award each other grades above the average. But the degree of reciprocity is not very high, revealing important within-pair variance. Table 3 reports the directed pair-specific intercepts $\hat{\nu}_{i j}$ derived from estimating $E S C_{i j t}=\psi_{j t}+\xi_{i j}+u_{i j t}$ by OLS, where $\psi_{j t}$ is the average score attained by country $j$ at time $t$ and $u_{i j t}$ is an error term. We refer to the empirical estimates of the intercepts $\hat{\xi}_{i j}$ as excess $s_{i j}$ since they measure the excess of the average (over time) score that $i$ allows to $j$ relative to the overall average (over all countries and time) that $j$ receives. Table 3 shows selected country relations where excess-grading is statistically significant at least in one direction. ${ }^{11}$ The expected country clustering readily emerges. For example, Cyprus awards to Greece an average of 7.41 points more than Greece receives on average; Greece reciprocates by awarding an excess of 6.26 points beyond the Cypriot mean score. Over-generous and reciprocal relationships can be found for many Scandinavian country pairs, and to a lesser extent for Mediterranean countries. However, relationships need not be reciprocal: Finland awards Italy an excess 3.10 points, but gets an average negative excess grade of -0.77 in return. France grades Great Britain 0.86 points below average, while the Brits treat France almost neutrally. ${ }^{12}$ Scandinavian and Mediterranean countries tend to reciprocally award scores below the respective averages (with the pair Denmark-Yugoslavia the notable exception). Not surprisingly, Cyprus and Turkey stand out as two countries that systematically award each other grades below average. Germany (and Austria) over-grade Turkey without being compensated; this is likely to reflect ethnic ties due to migration.

Table 3 reveals an intuitive pattern. Reciprocal positive excess grades occur within culturally close pairs; reciprocal negative excess grades appear for the

$\overline{11}$ See also Table 1 in Clerides and Stengos (2006).

12 This confirms the Duke of Wellington: "We always have been, we are, and I hope that we always shall be detested in France." (cited by Guiso et al., 2007, p. 1.). 
Table 3

ESC scores: Selected deviations from means

\begin{tabular}{|c|c|c|c|c|c|}
\hline Country $i$ & Country $j$ & excess $_{i j}$ & std. err. & excess $_{j i}$ & std. err. \\
\hline CYP & GRC & 7.41 & 0.65 & 6.26 & 0.65 \\
\hline ITA & PRT & 3.95 & 0.63 & 0.02 & 0.63 \\
\hline DNK & ISL & 3.27 & 0.72 & 2.05 & 0.72 \\
\hline FIN & ITA & 3.10 & 0.65 & -0.77 & 0.65 \\
\hline DNK & SWE & 2.99 & 0.55 & 1.98 & 0.55 \\
\hline ISL & SWE & 2.95 & 0.65 & 1.56 & 0.65 \\
\hline ESP & ITA & 2.95 & 0.63 & 1.70 & 0.63 \\
\hline CYP & YUG & 2.67 & 0.82 & 2.49 & 0.82 \\
\hline HRV & MLT & 2.52 & 0.78 & 3.17 & 0.78 \\
\hline TUR & YUG & 2.22 & 0.75 & 3.21 & 0.75 \\
\hline DNK & NOR & 2.04 & 0.57 & 0.79 & 0.57 \\
\hline GER & TUR & 1.79 & 0.53 & -0.70 & 0.53 \\
\hline CYP & ESP & 1.79 & 0.57 & -0.27 & 0.57 \\
\hline ESP & GRC & 1.77 & 0.54 & 2.62 & 0.54 \\
\hline ISL & NOR & 1.71 & 0.65 & 1.08 & 0.65 \\
\hline NOR & SWE & 1.56 & 0.50 & 2.64 & 0.50 \\
\hline BEL & NLD & 1.33 & 0.55 & 0.30 & 0.55 \\
\hline AUT & TUR & 1.12 & 0.55 & -0.21 & 0.55 \\
\hline FIN & SWE & 1.06 & 0.54 & 0.67 & 0.54 \\
\hline FRA & GBR & -0.86 & 0.49 & 0.18 & 0.49 \\
\hline ESP & NOR & -1.01 & 0.49 & -1.37 & 0.49 \\
\hline ESP & SWE & -1.39 & 0.49 & -1.20 & 0.49 \\
\hline ITA & SWE & -1.51 & 0.65 & -0.93 & 0.65 \\
\hline DNK & ESP & -1.66 & 0.55 & -0.39 & 0.55 \\
\hline ISR & ITA & -1.73 & 0.69 & -1.73 & 0.69 \\
\hline HRV & SWE & -1.76 & 0.78 & -3.06 & 0.78 \\
\hline DNK & HRV & -1.92 & 0.98 & -2.53 & 0.98 \\
\hline CYP & TUR & -2.09 & 0.58 & -1.22 & 0.58 \\
\hline DNK & YUG & -2.17 & 0.78 & 1.34 & 0.78 \\
\hline
\end{tabular}

Pair-specific intercepts, means adjusted. All estimates are significant at 10 percent level. All country pairs in the table occur at least 10 times in the data. Excess $s_{i j}$ denotes the score awarded by $i$ to $j$ in excess to $j$ 's average score.

usual suspects but are on average smaller than positive excess grades. Moreover, non-reciprocal behavior seems to be quite frequent. The (simple) correlation coefficient between excess $s_{i j}$ and excess $_{j i}$ is 35.07, the Spearman rank correlation coefficient is 27.81 ; both measures are statistically different from zero at the one percent level of significance.

There is plenty of anecdotal evidence that ESC scores reflect changes in atti- 
tudes and moods over time. For example, The Economist described the victory of Serbia in 2003 and that of Turkey in 2007 as signs that the other European countries perceive Serbia and Turkey as less culturally remote (May 29, 2003; May 17, 2007). The successes of Estonia and Latvia in 2001 and 2002, respectively, received similar comment (May 30, 2002). The success of Finland in 2006 was associated to the widespread perception of a successful 'Finnish model' (July 6, 2006). According to long-time commentator Terry Wogan from the BBC, the failure of Britain to earn a single point in 2003 was due to Britain's decision to back the United States in its attack on Iraq. ${ }^{13}$

While the examples cited above mark short-term effects, the data also reveals long-run trends. For example, the popularity of countries seems subject to cycles that are difficult to reconcile with underlying movements in musical quality. For example, The Economist relates the failure of France to win any contest since 1977 to the loss of French popularity and cultural clout in Europe (May 12, 2005). The example of Italy offers a similar, but less spectacular, picture. It is well possible that the popularity of Celtic culture (Ireland) will suffer the same fate. ${ }^{14}$

Gatherer (2006) provides systematic evidence for time shifts in bilateral popularity. He simulates matrices of 'unbiased' ESC score outcomes and compares them to actual voting. He shows that collusive voting alliances, described by several authors (e.g., Fenn et al., 2005) have shifted over time. The observed time pattern makes sense: France has lost its early central role to Englishspeaking countries (Ireland, Britain), which have then given way to Eastern Europe.

\footnotetext{
$\overline{13}$ BBC News "Turkish delight at Eurovision win", Saturday 24 May 2003. Moreover, while all those effects naturally have a country-time dimension, their reception across Europe and hence their importance for bilateral trade need not be identical. ${ }^{14}$ Figure 1 in the web appendix presents the time profile of multilateral unadjusted ESC scores earned by frequently participating countries.
} 


\section{Cultural proximity in the gravity model}

We base our theoretical model on the multi-country monopolistic competition model of trade (see Feenstra, 2004, for an overview). Each country $i$ is populated by a representative individual who derives utility from consuming different varieties of a differentiated good according to a standard CES function,

$$
U_{i t}=\sum_{j=1}^{C} a_{i j t}^{\frac{\sigma-1}{\sigma}} \sum_{z=1}^{n_{j t}}\left(m_{z i j t}\right)^{\frac{\sigma-1}{\sigma}},
$$

where $z$ denotes the index of a generic variety, $n_{j t}$ is the number of varieties produced in country $j$ at time $t$ and $\sigma>1$ is the elasticity of substitution between varieties. The quantity of consumption in country $i$ of variety $z$ from country $j$ is $m_{z i j t}$. Following Combes et al. (2005), we allow for a specific weight $a_{i j t} \geq 0$ to describe the special preference of the representative consumer in country $i$ for goods from country $j$.

All varieties from the same origin bear the same f.o.b. (ex factory) price $p_{j t}$ (reflecting symmetric production technologies), and iceberg ad-valorem trade costs payable for deliveries from $j$ to $i, t_{i j t} \geq 1$, do not depend on the characteristics of the varieties within a sector. Hence, the c.i.f. price (i.e., including trade costs) paid by consumers $p_{i j t}=p_{j t} t_{i j t}$ is the same for all varieties imported from $j$. It follows that consumed quantities $m_{z i j t}$ are identical for all $z$ so that we can omit the variety index in the sequel.

Maximizing (2) subject to an appropriate budget constraint, one derives country $i^{\prime} s$ demand quantity $m_{i j t}$ for a generic variety. Calculating the c.i.f. value of total imports from country $j$ at time $t$ as $M_{i j t}=n_{j t} p_{i j t} m_{i j t}$, we find ${ }^{15}$

$$
M_{i j t}=\left(\frac{a_{i j t}}{t_{i j t}}\right)^{\sigma-1} \mu_{i t} \phi_{j t} .
$$

The variables $\mu_{i t} \equiv E_{i t} P_{i t}^{\sigma-1}$ and $\phi_{j t} \equiv n_{j t} p_{j t}^{1-\sigma}$ collect terms that depend only on country $i^{\prime} s$ or $j^{\prime} s$ characteristics. $P_{i t}=\left[\sum_{j=1}^{C}\left(\frac{a_{i j t}}{t_{i j t}}\right)^{\sigma-1} p_{j t}^{1-\sigma} n_{j t}\right]^{\frac{1}{1-\sigma}}$ is the

\footnotetext{
$\overline{15}$ Note that Combes (2007) express imports in terms of quantities not values.
} 
aggregate price index and $E_{i t}$ denotes country $i^{\prime} s$ GDP.

For our empirical investigation, we do not need to close the model by explicitly specifying supply-side and equilibrium conditions. However, we need to clarify the role of cultural proximity in shaping bilateral trade flows. Cultural proximity affects the bilateral trade equation (3) in two ways. On the one hand, it lowers trade costs, $t_{i j t}$ : a higher total level of trust, the easier formation of business and/or social networks, or fewer misunderstandings related to non-verbal communication make expensive hedging measures and consulting services redundant. This is the trade-cost channel of cultural proximity. On the other hand, cultural proximity is also reflected in the bilateral affinity parameter $a_{i j t}$. A high value of $a_{i j t}$ means that the representative consumer in country $i$ puts a high value on products produced in country $j$. Equation 3 together with the assumption $\sigma>1$ implies that this situation leads to larger trade volumes. This is the preference channel of cultural proximity.

In our empirical set up, as indicated earlier, we capture cultural proximity $\Pi_{i j t}$ by the revealed degree of cultural proximity (quality adjusted) obtained from the ESC, $\tilde{\Pi}_{i j t}$, and by the more conventional measures, discussed in section 2.2, such as linguistic proximity, direct communication $D C_{i j}$, and open circuit communication $O C_{i j}$, the existence of common legal origins $\left(L A W_{i j}\right)$, the intensity of ethnic ties (log of bilateral migrant stock, $E T H_{i j}$ ), and the degree of religious proximity $\left(R E L_{i j}\right)$. Grouping the conventional indicators into the vector $\mathbf{K}_{i j}$, we posit

$$
\Pi_{i j t}=\tilde{\Pi}_{i j t}+\kappa \prime \cdot \mathbf{K}_{i j}
$$

where $\boldsymbol{\kappa}$ is a (column) vector of parameters. In principle, all components of $\mathbf{K}$ may be time-varying. However, there is only cross-sectional information available on these variables. Hence, the ESC scores are the only source of time-variant information about time-varying cultural proximity.

We now specify how country $i^{\prime} s$ cultural proximity to country $j$ is related to bilateral affinity and trade costs. We assume that country $i^{\prime} s$ preference for 
goods from $j, a_{i j t}$, depends on cultural proximity $\prod_{i j t}$ in the following way:

$$
\ln a_{i j t}=\alpha \Pi_{i j t}
$$

where $\alpha>0$. Similarly, we assume that trade costs $t_{i j t}$ also depend on $\Pi_{i j t}$. However, besides cultural proximity, there are at least three other fundamental determinants of trade costs: ${ }^{16}$ (i) Transportation costs, reflected by geographical distance $\left(D I S T_{i j}\right)$ and the existence of a common land border (adjacency, dummy variable $A D J_{i j}$ ); (ii) formal trade policy, measured by joint membership in a free trade agreement (dummy variable $F T A_{i j t}$ ); and (iii) costs of contracting and negotiation. The latter category is closely related to cultural proximity since higher trust and understanding amongst parties certainly lowers transaction costs. However, transaction costs can be low for reasons unrelated to cultural proximity, e.g., if a common legal system facilitates the write-up of contracts or if citizens in both countries master the language of some third country. We write iceberg trade costs as

$$
\ln t_{i j t}=\delta \ln D I S T_{i j}-\gamma A D J_{i j}-\varphi F T A_{i j t}-\pi \Pi_{i j t}
$$

We expect that all parameters $\delta, \gamma, \varphi$ and $\pi$ are positive.

Using a linearized version of the ESC score equation (1), together with equations (4), (5) and (6) in (3), we obtain the following log-linear gravity equation:

$$
\begin{aligned}
\ln M_{i j t}= & \eta E S C_{i j t} \\
& +\bar{\kappa}_{1} D C_{i j}+\bar{\kappa}_{2} O C_{i j}+\bar{\kappa}_{3} L A W_{i j}+\bar{\kappa}_{4} E T H_{i j}+\bar{\kappa}_{5} R E L_{i j} \\
& -\bar{\delta} \ln D I S T_{i j}+\bar{\gamma} A D J_{i j}+\bar{\varphi} F T A_{i j t} \\
& +\nu_{i t}+\nu_{j t}+D_{i j t}+\varepsilon_{i j t},
\end{aligned}
$$

where $\eta \equiv(\sigma-1)(\alpha+\pi), \bar{\kappa}_{k}=\eta \kappa_{k}$ and $\kappa_{k}$ being the coefficients associated to each element in the vector $\mathbf{K}_{i j}, \bar{\delta} \equiv(\sigma-1) \delta, \bar{\gamma} \equiv(\sigma-1) \gamma, \bar{\varphi} \equiv(\sigma-1) \varphi$, and $\varepsilon_{i j t} \equiv(1-\sigma)(\alpha+\pi) u_{i j t}$. The vectors $\nu_{i t}$ and $\nu_{j t}$ collect importer $\times$ year and exporter $\times$ year fixed effects to control for $\mu_{i t}$, and $\phi_{j t}$ (both of which have important unobserved components such as the true price index, the number of firms, or the price of a generic variety) as well as for song quality. Finally, $\overline{16}$ See Anderson and van Wincoop (2004) for a classification of different types of trade costs. 
$\varepsilon_{i j t}$ is the error term. The use of fixed effects makes the inclusion of GDP or price data redundant. It also frees us from the need to think about the choice of proper deflators for right and left-hand side variables of the gravity equation. ${ }^{17}$ Equation (7) contains only pair-specific variables, because countryspecific ones are perfectly controlled for by country-specific fixed effects. ${ }^{18}$

Our main parameters of interest are $\eta$ and the coefficients of the more standard measures of cultural proximity $\kappa_{1}$ to $\kappa_{4}$. These coefficients reflect both the trade cost (through $\pi$ ) and the preference channel (through $\alpha$ ).

\section{Quantifying the role of cultural proximity}

In this section, we first show a standard gravity equation without ESC scores, but with the standard variables such as common language, common legal origin, religious proximity, and ethnic ties as measures of cultural proximity. Second, we add ESC scores and show that the time and within-pair variance of that measure adds explanatory power to the gravity equation. What is more, we argue that our results suggest that ESC scores indeed reflect cultural proximity, while the standard measures may also reflect the costs of contracting and negotiation. Third, we document that imports and exports are affected differently by cultural proximity.

\subsection{A standard gravity equation}

We estimate equation (7), following the literature where $\eta$ is exogenously set to zero since ESC scores play no role. Using the sub-aggregates proposed by

17 Baldagi, Egger, and Pfaffermayr (2003) first proposed the use of interaction terms between country and time fixed effects in econometric gravity models, without, however, offering a theoretical rationale. The latter follows immediately from Anderson and van Wincoop (2003). Baier and Bergstrand (2007) use a similar strategy in their work on the effects of free trade agreements.

18 Absent endogeneity concerns (which we address in subsection 5.1), our empirical strategy allows consistent estimation of average effects; since changes in cultural proximity affect multilateral resistance terms (price indices) differently, the true coefficient is not constant across countries (Anderson and van Wincoop, 2003). 
Rauch (1999), we distinguish between homogeneous goods and differentiated goods. Homogeneous goods are defined as goods that are transacted on organized exchanges. ${ }^{19}$ For these goods cultural proximity should be largely irrelevant.

Table 4 provides the results of running specification (7). All regressions use a full set of interactions between exporter and importer fixed effects with year dummies. Since our data contain observations for the same country pair over time, we correct the standard errors for correlation within country pairs.

Table 4

Standard gravity equation

Dep.var.: Ln value of bilateral imports

\begin{tabular}{lllllll}
\hline \multirow{2}{*}{ Variable } & \multicolumn{2}{c}{ Aggregate Imports } & \multicolumn{2}{l}{ Differentiated Goods } & \multicolumn{2}{l}{ Homogeneous Goods } \\
& $(\mathrm{S} 1)$ & $(\mathrm{S} 2)$ & $(\mathrm{S} 3)$ & $(\mathrm{S} 4)$ & $(\mathrm{S} 5)$ & $(\mathrm{S} 6)$ \\
\hline Ln Distance & $-0.986^{* * *}$ & $-0.732^{* * *}$ & $-0.837^{* * *}$ & $-0.551^{* * *}$ & $-0.998^{* * *}$ & $-0.864^{* * *}$ \\
& $(0.087)$ & $(0.071)$ & $(0.087)$ & $(0.064)$ & $(0.13)$ & $(0.13)$ \\
Adjacency & $0.412^{* * *}$ & -0.154 & $0.543^{* * *}$ & -0.0700 & $1.050^{* * *}$ & $0.602^{* * *}$ \\
Both country in same FTA & $(0.14)$ & $(0.10)$ & $(0.14)$ & $(0.12)$ & $(0.18)$ & $(0.19)$ \\
& 0.0805 & -0.00385 & 0.0342 & -0.0621 & $0.453^{* * *}$ & $0.375^{* * *}$ \\
Direct communication & $(0.052)$ & $(0.044)$ & $(0.059)$ & $(0.047)$ & $(0.10)$ & $(0.10)$ \\
& & -0.679 & & -0.136 & & -0.256 \\
Open-circuit communication & & $(0.51)$ & & $(0.26)$ & & $(1.01)$ \\
& & $1.145^{* *}$ & & $0.747^{* * *}$ & & 0.911 \\
Common legal origin & & $(0.49)$ & & $(0.24)$ & & $(0.81)$ \\
Religious proximity & & $0.418^{* * *}$ & & $0.401^{* * *}$ & & $0.452^{* * *}$ \\
& & $(0.069)$ & & $(0.069)$ & & $(0.13)$ \\
Ethnic ties & & 0.166 & & $0.284^{* *}$ & & 0.121 \\
& & $(0.12)$ & & $(0.12)$ & & $(0.24)$ \\
\hline Observations & & $0.223^{* * *}$ & & $0.233^{* * *}$ & & $0.0914^{* *}$ \\
AdjustedR & & $(0.026)$ & & $(0.025)$ & & $(0.043)$ \\
RMSE & 10,560 & 10,560 & 7,826 & 7,826 & 7,161 & 7,161 \\
\hline
\end{tabular}

All regressions contain exporter $\times$ year and importer $\times$ year fixed effects. Standard errors (in brackets) have been adjusted for clustering around country pairs. $*, * * * * *$ denote statistical significance at the 10,5, and 1 percent levels, respectively. Sample sizes differ between aggregate trade, differentiated goods, and homogeneous goods due to the existence of zero values and missings in disaggregated trade data.

19 We report findings for Rauch's conservative aggregation scheme (which minimizes the number of goods that are classified as either traded on an organized exchange or reference priced). Our results remain qualitatively similar if the liberal aggregation scheme is used. Results for Rauch's third category, reference-priced goods, are very similar to those for homogeneous goods and available upon request. 
Column (S1) in Table 4 reports a parsimonious benchmark equation for aggregate trade, which does not include the cultural proximity variables. In line with existing research, the elasticity of bilateral trade with respect to geographical distance is very close to unity. Also the effect of a common border (adjacency) is of familiar size: all else equal, neighboring countries trade about $41 \%$ more than countries without a common border. In contrast, column (S1) suggests that a free trade area does not increase trade between its members; this is a common result in this type of setup (Baier and Bergstrand, 2007).

Column (S2) adds direct and open-circuit communication, common origin of the legal system, ethnic ties and religious proximity as measures of cultural proximity into the regression. The presence of these variables reduces the importance of geography: the distance coefficient falls from unity to about 0.73 , while adjacency now turns out to reduce trade - albeit at marginal statistical significance. Two countries in which translation, if required, is supposed to be costless, trade about $115 \%$ more. Direct communication does not influence bilateral trade between European countries. ${ }^{20}$ A common legal system boosts trade by $42 \%$ and an increase in the migrant population by 1 percentage point turns out to boost bilateral trade by 0.22 percentage points. Again, these magnitudes are in line with findings in the literature.

Columns (S3) to (S6) repeat the above exercise for the subaggregates of differentiated and homogeneous goods. Since the independent variable has been constructed from fairly disaggregated trade data in which missing values abound, the number of observations is lower than for aggregate data. ${ }^{21} \mathrm{~A}$ couple of differences between the two subaggregates stand out. First, geography-based variables matter more strongly for homogeneous goods. This is not surprising, since the higher elasticity of substitution for homogeneous goods drives up parameter estimates; see equation (7). This pattern carries over, albeit at a lower extent, to common legal system. However, the effect of ethnic ties is

\footnotetext{
${ }^{20}$ Notice that the direct communication variable is mainly composed by zero values in our sample of European countries. This may reflect the differences to the results reported by Melitz (2008), who draws on a sample with much larger country coverage.

21 Aggregate bilateral data has been constructed by the IMF. In that data base, many missing values are imputed by experts.
} 
much smaller with homogeneous goods and the effects of open-circuit communication and religious proximity - statistically significant with differentiated goods - disappear with homogeneous goods. We may conclude that the evidence hints at a much larger role of cultural proximity for differentiated goods than for homogeneous ones.

\subsection{The role of ESC scores for bilateral trade volumes}

The variables included in Table 4 - while reflecting cultural proximity - may do so imperfectly (especially since they are time-constant and symmetric). Further, they may also foster trade directly by reducing communication costs. In this subsection we extend the above analysis and include ESC scores as an additional explanatory variable in the gravity framework. ESC scores affect trade only through cultural proximity, since there is no direct effect on contracting and negotiation costs. Table 5 reports our results.

Let us first focus on country $i^{\prime} s$ aggregate imports from $j$ (columns (S1) to (S3)). Specification (S1) regresses $i^{\prime} s$ imports on the scores that $i$ allots to $j$. Specification (S2) instead inverts the direction of scoring and uses the ESC scores that $j$ awards to $i$. Column (S3) uses both directions in a single equation. We include a dummy $D_{i j t}$ that takes the value of one if $E S C_{i j t}>0$ and zero otherwise (similarly for $E S C_{j i t}$ ). ${ }^{22}$ In all models, the ESC variables turn out statistically highly significant and positive. Measures for the more conventional cultural variables such as common language, legal system, religious proximity, and ethnic ties continue to matter, their marginal effects being slightly smaller than those reported in regressions without the ESC scores.

In section 2.2, we have argued that cultural proximity may have a low degree of reciprocity. This conjecture implies that high scores awarded by country $i$ to $j$ should foster $i^{\prime} s$ imports from $j$, but high scores awarded by $j$ to $i$ need not increase $i^{\prime} s$ imports (but rather $j^{\prime} s$ ). This hypothesis is confirmed

$\overline{22}$ We do not report the estimates of $D_{i j t}$ since it is mostly insignificant. We owe this dummy variable strategy to an anonymous referee. The bilateral trade variable is in fact not affected by the failure to rank songs below 1 to 10 so that our estimation strategy is not plagued by non-random sampling. 


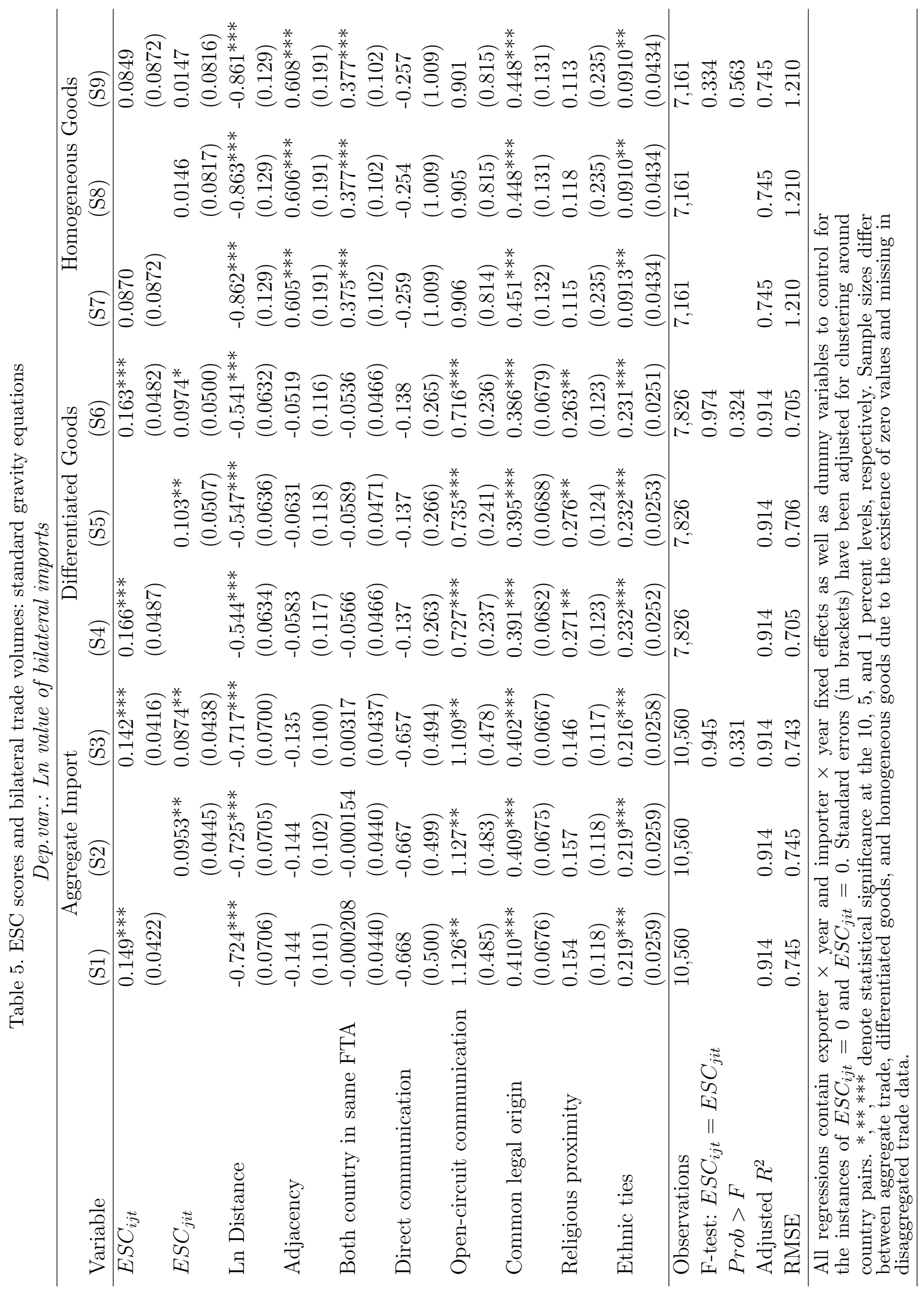


in specification (S2). The coefficient on the $E S C_{j i t}$ variable is positive, but smaller and estimated with a lower degree of precision than the $E S C_{i j t}$ variable in (S1). The effect on aggregate imports of moving the ESC for the importing country from 0 to 1 is $14.9 \%$ in specification (S1). The effect of the ESC scores for the exporting country is $9.53 \%$ in specification (S2).

Specification (S3) uses both ESC variables simultaneously in the same regression. Estimated coefficients are strikingly close to those obtained separately in columns (S1) and (S2). This fact can be interpreted as a lack of strong correlation between $E S C_{i j t}$ and $E S C_{j i t}$ and therefore as a sign of low reciprocity. Moreover, country $i^{\prime} s$ imports receive a stronger boost from higher realizations of $E S C_{i j t}$ than $E S C_{j i t}$. An F-test on the difference between the two estimates of the ESC scores in specification (S3) does not allow rejecting the conclusion that this difference is statistically zero. But the fact that both variables enter signficantly and simultaneously argues the other way.

Columns (S4) to (S6) and (S7) to (S9) repeat this exercise for differentiated and homogeneous goods, respectively. Results for the subaggregate of differentiated goods are comparable to those for aggregate trade. Results for homogeneous goods, however, are different. Most strikingly, we find that ESC scores matter for trade in differentiated goods regardless of the exact specification of the model, while they are irrelevant for trade in homogeneous goods. Moving the ESC for the importing country from 0 to 1 impacts trade in differentiated goods by $16.6 \%$ in specification (S4). The effect of the ESC scores for the exporting country is $10.3 \%$ in specification (S5).

The failure of ESC scores to show up significantly in the specifications explaining trade in homogeneous goods is in contrast to the conventional measures of cultural proximity, such as common legal origin and ethnic ties whose effects on bilateral trade come out positive and statistically significant. Moreover, the adjacency variable turn out significant for trade of homogeneous goods. ${ }^{23}$ The literature suggests that informal trade costs, such as those represented by

$\overline{23}$ FTA membership seems to matter for homogeneous goods, but is unimportant for trade in differentiated goods. This is a surprising and interesting result that may be worth further investigation. 
cultural distance should matter more for complex differentiated goods, which are difficult to contract over. Middlemen selling homogeneous goods usually do not reveal the country of production, so that the operation of a preference channel would be hard to defend. Taking the extreme position that cultural proximity is entirely irrelevant for homogeneous goods, the conventional indicators must affect trade costs through a mechanism unrelated to cultural proximity. Hence, this evidence supports the interpretation of ESC scores as operating strictly through an influence on tastes.

Following Anderson and van Wincoop (2004), we can also interpret the ESC coefficients in term of an accross-the-board tariff equivalent. In order to do this we assume that the elasticity of substitution to 6 for aggregate trade, to 4 for differentiated goods, and to 12 for homogeneous goods. Thus, moving $E S C_{i j t}$ scores from 0 to 1 is equivalent to reducing tariff by 2.37 for aggregate imports $(0.142 \times 100 / 6)$ and by 4.1 percentage points for differentiated products $(0.163 \times 100 / 4)$.

\section{Extensions}

In this section we present a number of critical extensions dealing with the endogeneity of cultural proximity and the omitted variable problem. We also present several robustness checks to assess our main results.

\subsection{Controlling for endogeneity}

There is a growing theoretical literature on the endogenous emergence and evolution of cultural identities (see the recent surveys by Fernandez, 2007 and Guiso et al., 2009). This literature identifies determinants that drive both economic outcomes and cultural traits. In the context of the present paper, positive shocks on bilateral trade volumes could lead to cultural convergence so that two countries end up with a higher degree of cultural proximity than before the shock. Regressing ESC scores on lagged bilateral trade (imports, 
exports, or the sum thereof), and controlling for dyadic fixed effects, we do not find any first-order evidence for endogeneity. This result is confirmed in a number of models that differ with respect to their treatment of the nonlinearity of ESC scores (OLS, Tobit, and Poisson). But while this evidence is suggestive, it is not a rigorous proof on the absence of endogeneity. It is still possible that OLS estimates suffer from simultaneity bias. Dealing with the simultaneity problem requires an instrumentation strategy.

Following Combes et al. (2005), we exploit the time structure of our data to estimate the effect of an exogenous change in cultural proximity. It is reasonable to assume that past ESC scores (e.g., dating from $t-5$ ), are not causally affected by current bilateral trade volumes (at time $t$ ). In other words, current shocks in the gravity equation are uncorrelated to lagged ESC values. Then, past ESC scores are valid instruments, provided that they predict current scores sufficiently well.

Table 6 presents instrumental variable 2SLS regressions. ${ }^{24}$ As usual, we compare aggregate trade, trade in differentiated goods, and trade in homogeneous goods and either use $E S C_{i j t}$ and $E S C_{j i t}$ separately (specifications (1), (2), (4), (5), (7), (8)) or simultaneously (specifications (3), (6), and (9)). The first-stage regressions typically have F-statistics well beyond the usual ruleof-thumb value of 10 . We also report the Durbin and Wu-Hausman statistics. They do not allow to test exogeneity of the regressors per se, but whether the coefficients of more-efficient OLS estimation differ significantly from the coefficients of consistent but less efficient 2SLS estimation. Typically, we have to reject exogeneity at high degrees of significance; specifications (S5) and (S8) are notable exceptions. Hence, in general, instrumentation is required, and the proposed instrumentation strategy is valid. ${ }^{25}$

The IV results confirm a positive and significant effect of ESC scores on bilateral trade. Typically, the regressions reveal that the country $i^{\prime} s$ imports are

\footnotetext{
24 Results based on GMM or limited information maximum likelihood methods perform very similarly.

${ }_{25}$ The first stage regressions signal that 5-year lags of scores are valid instruments. Shorter lag structures work as well, but to the extent that bilateral trade flows are persistent, are less suited as instruments. Longer lags yield first stage regressions with fairly low F statistics.
} 
more strongly spurred by higher realizations of $E S C_{i j t}$ than of $E S C_{j i t}$, which confirms a finding presented in Table 5. However, as the $\chi^{2}$ tests on equality of coefficients performed in columns (3), (6) and (9) show, we do not always have strong statistical evidence for the differential impact of these two variables. Also note that the $\chi^{2}$ test on $E S C_{i j t}=E S C_{i j t}=0$ typically fails, so that cultural proximity of some type always matters in the proposed models. The IV results imply that OLS biases the effect of ESC scores downwards. On the one hand, one would expect that a positive shock on trade increases cultural proximity. However, on the other hand, it is important to notice that the IV-regressions not only remedy a potential endogeneity bias, they also help to deal with measurement error, which biases OLS estimates towards zero. While our analysis leaves little doubt on the meaningfulness of ESC scores as measures of cultural proximity, it is also obvious that these scores are very noisy proxies.

Guiso et al. (2009) and Combes et al. (2005) also discuss attempts to use IV strategies in similar setups, where the level of bilateral economic activity is regressed on various measures of bilateral trust or information. Both papers find that OLS strongly underestimates the true causal effects, just as we find in our 2SLS regressions. Both papers conclude that 'reverse causality is not a major problem'. This is a strong conclusion; however, we have found no contradictory evidence.

\subsection{Controlling for unobserved factors}

The volume of trade between two countries and the degree of cultural proximity between them may both depend on bilateral factors that remain unobserved by the econometrician. Often, these factors are related to initial conditions. There are at least three examples of unobserved factors that may be relevant in the context of this paper.

First, cross-border transactions require and condition social interactions between individuals, which may change their incentives to acquire certain skills or invest in certain networks. For example, interactions with foreign trading 
partners at some initial point in time might lead to mutual learning, which may trigger convergence of cultural characteristics as certain norms or behavioral standards are adopted. In turn, this generates more trade, potentially through both the trade cost and the preference channel. Hence, current levels of bilateral trade and cultural proximity positively depend on the initial degree of cultural proximity. This, in turn, means that failing to control for initial conditions distorts estimates upwards due to omitted variable bias.

A second problem, closely related to the first, is habit formation. The preference for a country's specific varieties may be stronger if the representative consumer in the partner country already heavily consumes those varieties. Again, it is the unobserved initial bilateral trade volume that may have led to the endogenous formation of consumption habits and, hence, bias estimates.

Third, the volume of trade between two countries and the degree of cultural proximity between them may both depend on geographical factors. For example, bilateral migration between two countries may affect cultural proximity and trade alike. However, one set of determinants for migration is geographical distance or adjacency - two factors that we can easily control for. The other set of determinants has to do with income levels, and those depend on multilateral trade and not bilateral trade. In our regressions we also control for aggregate trade, since we have included country $\times$ year fixed effects. However, there may be remaining unobserved bilateral determinants of migration.

One way to deal with initial conditions is to use dyad-specific fixed effects. In the presence of those effects, the influence of the ESC scores depends entirely on their movement over time. The cross-sectional effects of the scores are absorbed by the dyadic fixed effects. Baier and Bergstrand (2007) successfully use this strategy in the gravity equation context. We estimate the following 'dyadic fixed effects equation' (DFEE) model:

$$
\ln M_{i j t}=\eta E S C_{i j t}+\bar{\varphi} F T A_{i j t}+\nu_{i t}+\nu_{j t}+\nu_{i j}+D_{i j t}+\varepsilon_{i j t}
$$

where $\nu_{i j}$ denotes the comprehensive set of country-pair specific fixed effects. Compared to equation (7), the inclusion of $\nu_{i j}$ makes all time-invariant bi- 


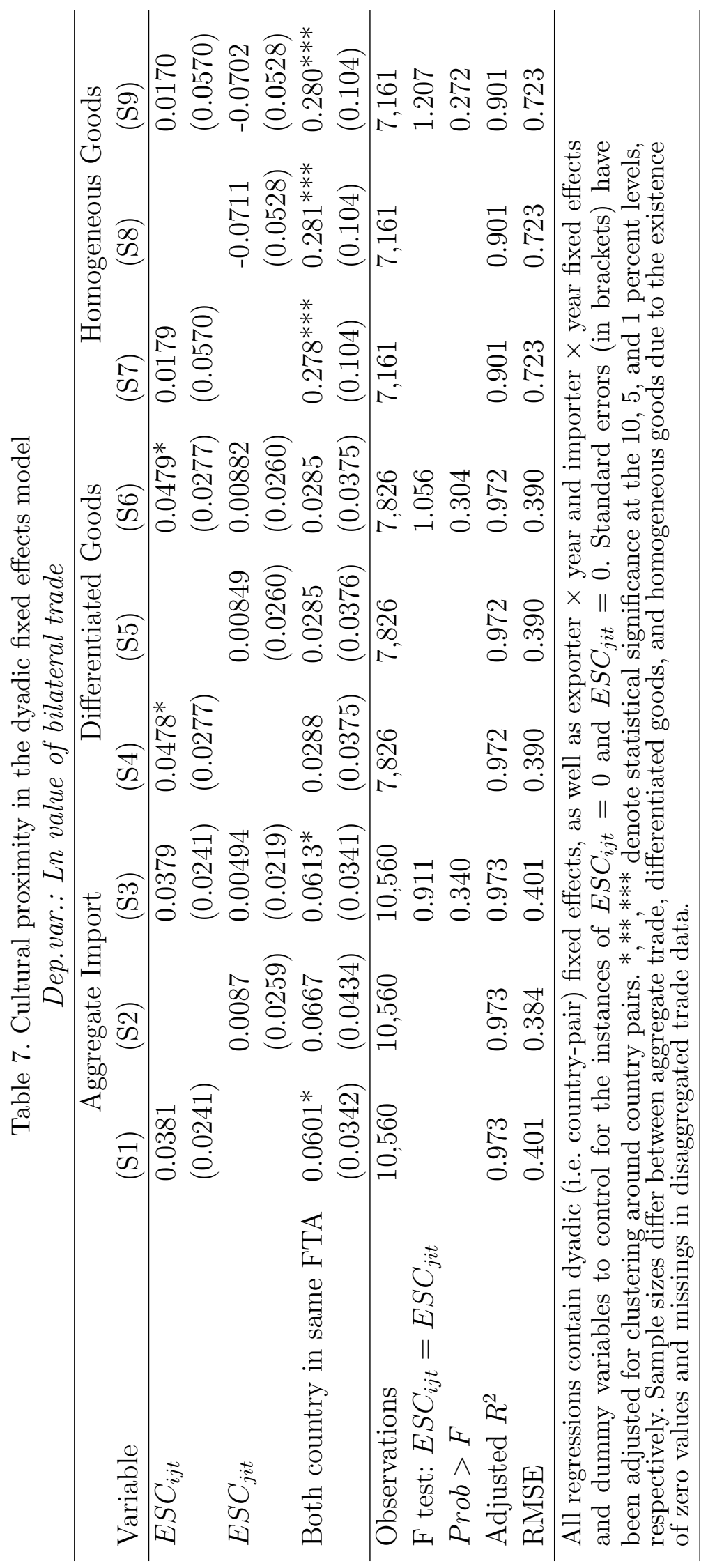


lateral determinants redundant. In particular, variables such as common language, common legal origin, etc., of trade flows drop out.

Table 7 reports the results from running regression (8) on our data set. As always, we differentiate between aggregate trade, trade in differentiated goods, and trade in homogeneous goods, but also between ESC scores for the importing and the exporting country. Since identification of the coefficients draws only on time variance, it becomes more difficult to find significant results. Yet with dyadic and country $\times$ year fixed effects included in the regression, we still find that ESC scores retain a positive and statistically significant influence on bilateral trade but only the in the case of trade in differentiated goods and only for country i's imports from j; see columns (S4) and (S5). The significant influence on bilateral trade in differentiated goods - now smaller than before - also holds up when both ESC measures are used simultaneously in the regression; see column (S6). Moving $E S C_{i j t}$ scores from 0 to 1 would be equivalent to reducing an ad valorem tariff by 1.20 percentage points in specification $(\mathrm{S} 6){ }^{26}$

\subsection{Additional robustness checks}

We have carried out two additional robustness checks, which can be consulted in the web appendix to this paper. One has to do with the switch from jurybased voting to televoting which occurred in 1998. Since our data extends from 1975 to 2003, one may wonder whether our results are driven by this switch in the rules of the contest. Table 1 shows regression results for the period 1975-1998, thereby drawing only on scores established by juries rather than by televoting. Our main results remain fully intact qualitatively. The total pro-trade effect of cultural proximity turns out slightly lower. The effect of the ESC scores for the exporting country turns out insignificant. For homogeneous goods, there is no robust effect of cultural proximity on trade, as in the main body of the paper.

$\overline{26} 0.0479 \times 100 / 4$ 
One may also question to what extent our results are driven by changes in bilateral migration stocks. The country that sent most immigrants to Europe during the period under investigation has been Turkey. Most of Turkish emigrants went to Germany. The bilateral stocks of immigrants at the start of our sample changed little since then due to restrictive immigration policies (Boeri and Brücker, 2005). Another test we provide then is to exclude is to exclude the dyad-specific fixed effects for Turkey as the sending country and to leave out the German-Turkish pair from our regressions in Table 2. The results resemble the earlier ones with all of the dyadic-specific effects.

\section{Conclusions}

There are many anecdotal hints that cultural proximity is a major determinant of bilateral trade volumes. However, empirical quantification and testing are difficult due to the elusiveness of the concept and lack of observability. The existing literature tries to account for cultural proximity by including variables such as common language, common legal origins, religious proximity, or ethnic ties. These indicators are certainly connected to cultural affinity between nations; they do, however, also capture other things related to the cost of contracting and negotiation that do not have anything to do with culture. We show that there is more to cultural proximity than what the conventional variables allow.

In this paper we draw on bilateral score data from the Eurovision Song Contest (ESC), a very popular pan-European television show, to construct a measure of cultural proximity which varies over time and within country pairs, and that correlates strongly with conventional indicators. Within the framework of a theory-grounded gravity model, we show that our measure positively affects trade in differentiated goods, even after controlling for the conventional measures used in the literature. Further, ESC scores do not add any explanatory power to gravity equations for goods that are traded on organized exchanges while the conventional indicators continue to matter. This is perfectly sensible. Since cultural proximity should not matter when direct contacts between sell- 
ers and buyers are not required. This finding suggests that ESC scores indeed reflect cultural proximity alone while the standard variables are also related to the costs of negotiating and contracting.

These results are surprisingly robust. We are able to reject that they are driven by simultaneity bias. They also survive the inclusion of country-pair specific fixed effects so that our baseline findings are not due to the omission of unobserved factors neither. Hence, our study highlights the overall importance of cultural proximity as well as the role of its time-varying and asymmetric nature for the determination of bilateral trade volumes. 


\section{Summary Statistics and Data Sources}

Our dataset and the web appendix can be downloaded at http://team.univparis1.fr/teamperso/toubal/papers/CP/CP.html.

Aggregate imports. Aggregate bilateral import flows (measured c.i.f.) are from the IMF's Direction of Trade Statistics (DoTS) CDROM (July 2006 edition) for the period 1975-2003.

Trade in differentiated and homogeneous goods. The data has been constructed by aggregating SITC4 rev. 2 trade data (c.i.f.) prepared by Feenstra et al. (2005) according to Rauch's (1999) 'conservative' classification of 4 digit SITC goods for the period 1975-2000.

Raw ESC scores. Data are from http://www.kolumbus.fi/jarpen/. An alternative website is http://nul-points.net/.

Adjusted ESC scores. Adjusted ESC scores are the residual of a regression of raw ESC scores on a set of song dummies.

Conventional measures of cultural proximity. We are very thankful to Jacques Melitz for sharing his data on languages. The variables have been computed as in Melitz (2008). We add Russian to his major direct communication languages since we have bilateral trade data for Russia. The measure 'common legal origin' is taken from La Porta et al. (1999) and distinguishes between a Latin, a Scandinavian, a British, and a Germanic system.

Following Alesina et al. (2000), 'religious proximity' is constructed as follows: Using mid-1990ies Census data ${ }^{27}$, we compute the shares $s_{r i}$ of adherents to religion $r$ ( Catholics, Protestants, orthodox Christians, Muslims, Jews, atheists, and non-religious persons) in total population of country $i$. Then, we compute a bilateral index $\rho_{i j}=\sum_{r} s_{r i} s_{r j}$, with $\rho_{i j} \in[0,1]$. This measure reaches a maximum value of 0.85 for the dyad Poland-Malta, and is minimum, 0.001, for the pair Poland-Turkey.

$\overline{27}$ The data are freely available on www.worldchristiandatabase.org and coincide closely with entries in the CIA fact book and other sources. 


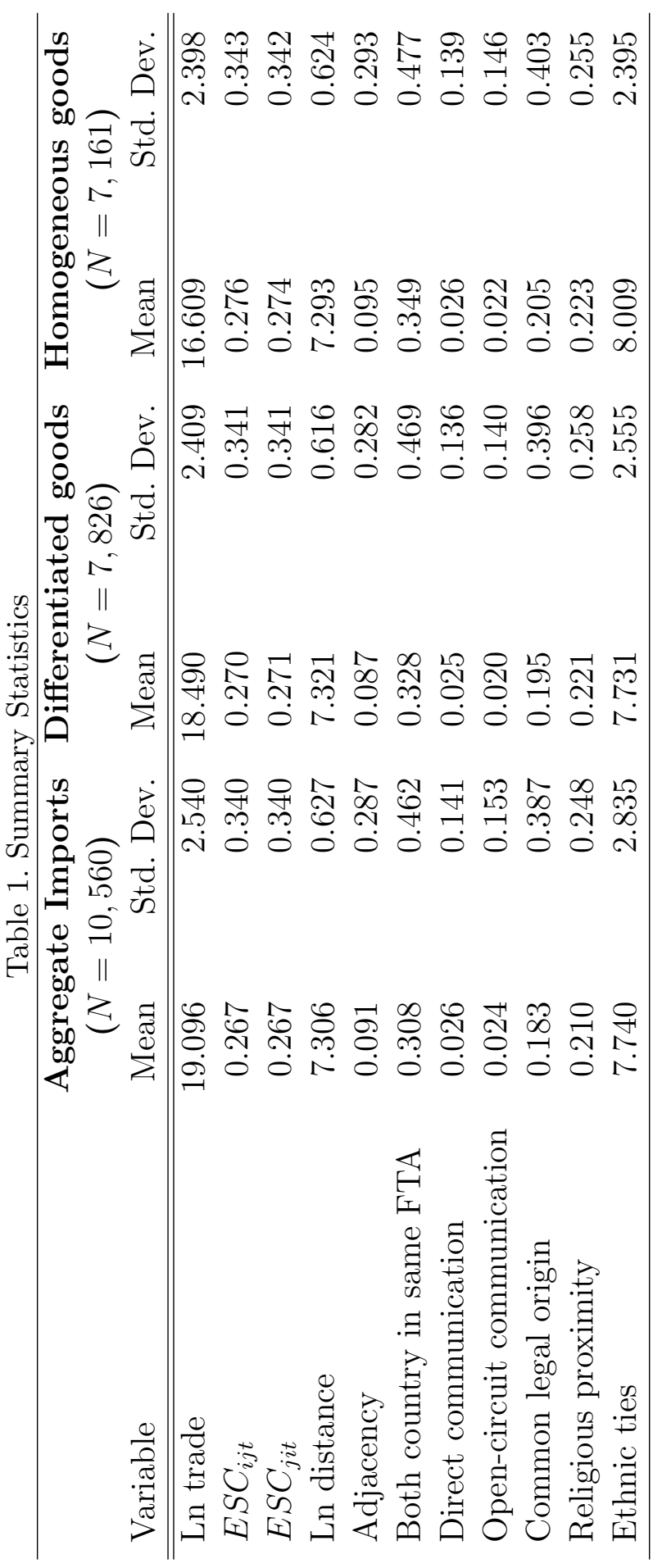


As a measure of ethnic ties, we use the stock of foreign born individuals by country of birth, provided by the OECD and discussed in Dumont and Lemaitre (2005). Our regressions include the natural logarithm of that stock.

Geographical data. Geographical distance and adjacency are from the CEPII in Paris. ${ }^{28}$

Free trade agreements. Data is from Baier and Bergstrand (2006) and updated to account for the pre-EU membership Europe agreements signed by East European countries with the EU (WTO website).

\footnotetext{
$\overline{28}$ The CEPII data can be downloaded from www. cepii.fr/anglaisgraph/bdd/distances.htm.
} 


\section{References}

- Alesina, A., Dollar, D., 2000. Who Gives Foreign Aid to Whom and Why. Journal of Economic Growth 5, 33-64.

- Algan, Y., and Cahuc, P., 2007. Social Attitudes and Macroeconomic Performance: An Epidemiological Approach. Mimeo: Paris School of Economics.

- Anderson, J.E., Van Wincoop, E., 2003, Gravity with Gravitas: A Solution to the Border Puzzle. American Economic Review 03(1): 170-192.

- Anderson, J.E., Van Wincoop, E., 2004, Trade Costs. Journal of Economic Literature 32(3): 691-751.

- Baier, S.L., Bergstrand, J.H., 2007, Do Free Trade Agreements Actually Increase Members' International Trade? Journal of International Economics 71(1): 72-95.

- Baltagi, B.H., Egger, P., Pfaffermayr, M., 2003, A Generalized Design For Bilateral Trade Flow Models. Economics Letters 80: 391-397.

- Blum, B., and Goldfarb A., 2006. Does the Internet Defy the Law of Gravity. Journal of International Economics 70(2): 384-405.

- Boeri, T., and Brücker, H., 2005. Why are Europeans so tough on migrants? Economic Policy 44: 629-703.

- Boisso, D., Ferrantino, M., 1997, Economic Distance, Cultural Distance, and Openness in International Trade: Empirical Puzzles. Journal of Economic Integration 12(4): 456-484.

- Boeri, T., and Brücker, H., 2005. Why Europeans Are So Tough on Migrants. Economic Policy, October 2005 : 629-703.

- Clerides, S., Stengos, T., 2006. Love thy Neighbor, Love thy Kin: Voting Biases in the Eurovision Song Contest. Mimeo: University of Cyprus.

- Combes, P-P., M. Lafourcade and T. Mayer, 2005. The Trade Creating Effects of Business and Social Networks: Evidence from France, Journal of International Economics 66:1-29.

- Disdier, A.C., Mayer, T., 2007. Je T'aime, Moi Non Plus. Bilateral Opinions and International Trade. European Journal of Political Economy 23: 11401159.

- Disdier, A.C., Tai, S.H.T., Fontagné, L., and Mayer, T., 2007. Bilateral 
Trade of Cultural Goods. Mimeo: University of Paris I.

- Dumont, J.-C. and Lemaitre, G., 2005, Counting immigrants and expatriates: A new perspective. OECD Social, Employment and MigrationWorking Paper 25.

- Feenstra, R. C., 2004. Advanced International Trade. Theory and Evidence. Princeton: Princeton University Press.

- Feenstra, R. C., Lipsey, R.E., Deng, H., Ma, A.C., and Mo, H., 2005. World Trade Flows: 1962-2000. NBER Working Paper 11040.

- Felbermayr, G., Toubal, F., 2006. Cultural Proximity and Trade. Tübinger Diskussionsbeitrag Nr. 305.

- Fenn, D., O. Suleman, Efstathiou, J., Johnson, N.F., 2006. How does Europe Make Its Mind Up? Connections, cliques, and compatibility between countries in the Eurovision Song Contest. Physica A 360(2): 576-598.

- Fernandez, R., 2007. Culture and Economics. New Palgrave Dictionary of Economics, 2nd ed., edited by Durlauf, S.N., and Blume, L.E., Palgrave McMillan, New York.

- Frankel,, J.A., 1997. Regional Trading Blocs in the World Economic System. Institute for International Economics.

- Gatherer, D., 2006. Comparison of Eurovision Song Contest Simulation with Actual Results Reveals Shifting Patterns of Collusive Voting Alliances. Journal of Artificial Societies and Social Simulation 9(2); http://jasss.soc.surrey.ac.uk/9/2/1.html.

- Ginsburgh, V., Noury, A., 2008. The Eurovision Song Contest. Is voting political or cultural, European Journal of Political Economy 24(1): 41-52..

- Ginsburgh, V., 2005. Languages, Genes, and Cultures. Journal of Cultural Economics 29(1), 1-17.

- Giuliano, P., Spilimbergo, A., and Tonon, G., 2006. Genetic, Cultural and Geographical Distances. IZA Working Paper 2229.

- Guiso, L., Sapienza, P., and Zingales, L., 2009. Cultural Biases in Economic Exchange? The Quarterly Journal of Economics, forthcoming.

- Guiso, L., Sapienza, P., and Zingales, L., 2006. Does Culture Affect Economic Outcomes? Journal of Economic Perspectives 20(2): 23-48.

- Greene, W.H., 2008, Econometric Analysis, Sixth Edition, Pearson, New Jersey. 
- Haan, M.A., Djikstra, G.S., Dijkstra, P.T., 2005. Expert Judgment versus Public Opinion. Evidence from the Eurovision Song Contest. Journal of Cultural Economics 29(1): 59-78.

- Huang, R.R., 2007. Distance and Trade: Disentangling Unfamiliarity Effects and Transportation Cost Effects. European Economic Review 51: 161-181.

- La Porta, R., Shleifer, A., Vishny, R.W., Lopez Da Silanes, F., 1998. Law and Finance. Journal of Political Economy 106(6).

- Melitz, J., 2008, Language and Foreign Trade, European Economic Review 52(4): 667-699.

- Rauch, J.E., 1999. Networks Versus Markets in International Trade. Journal of International Economics 48(1): 7-35.

- Rauch, J.E., Trindade, V., 2002. Ethnic Chinese Networks in International Trade. Review of Economics and Statistics 84(1): 116-130

- Rose, A.K., 2004. Do We Really Know that the WTO raises trade? American Economic Review 94(1): 98-114.

- Spierdijek, L. and Vellekoop, M., 2008. The structure of bias in peer voting systems: lessons from the Eurovision Song Contest. Empirical Economics: DOI 10.1007/s00181-008-0202-5.

- Spolaore, E., and Wacziarg, R., 2009. The Diffusion of Development. Quarterly Journal of Economics, forthcoming.

- Straubhaar, J., 2002. (Re)asserting national television and national identity against the global, regional and local levels of world television. In J. M. Chan and B. T. McIntyre (eds.): In search of boundaries. Communication, nationStates and cultural identities. Westport, Connecticut: Ablex Publishing.

- Tabellini, G., 2008. Institutions and Culture. Journal of the European Economic Association 6(2-3): 255-294.

- Yair G. 1995. 'Unite Unite Europe' The political and cultural structures of Europe as reflected in the Eurovision Song Contest. Social Networks 17(2): $147-161$.

\section{Web Appendix: Not to be Published}

This Appendix provides additional information and tables to Cultural Prox- 
imity and International Trade. Please also refer to Felbermayr and Toubal, Tübinger Diskussionsbeitrag 305 at

http://team.univ-paris1.fr/teamperso/toubal/papers/CP/dpversion.pdf.

\subsection{Time behavior of multilateral ESC scores}
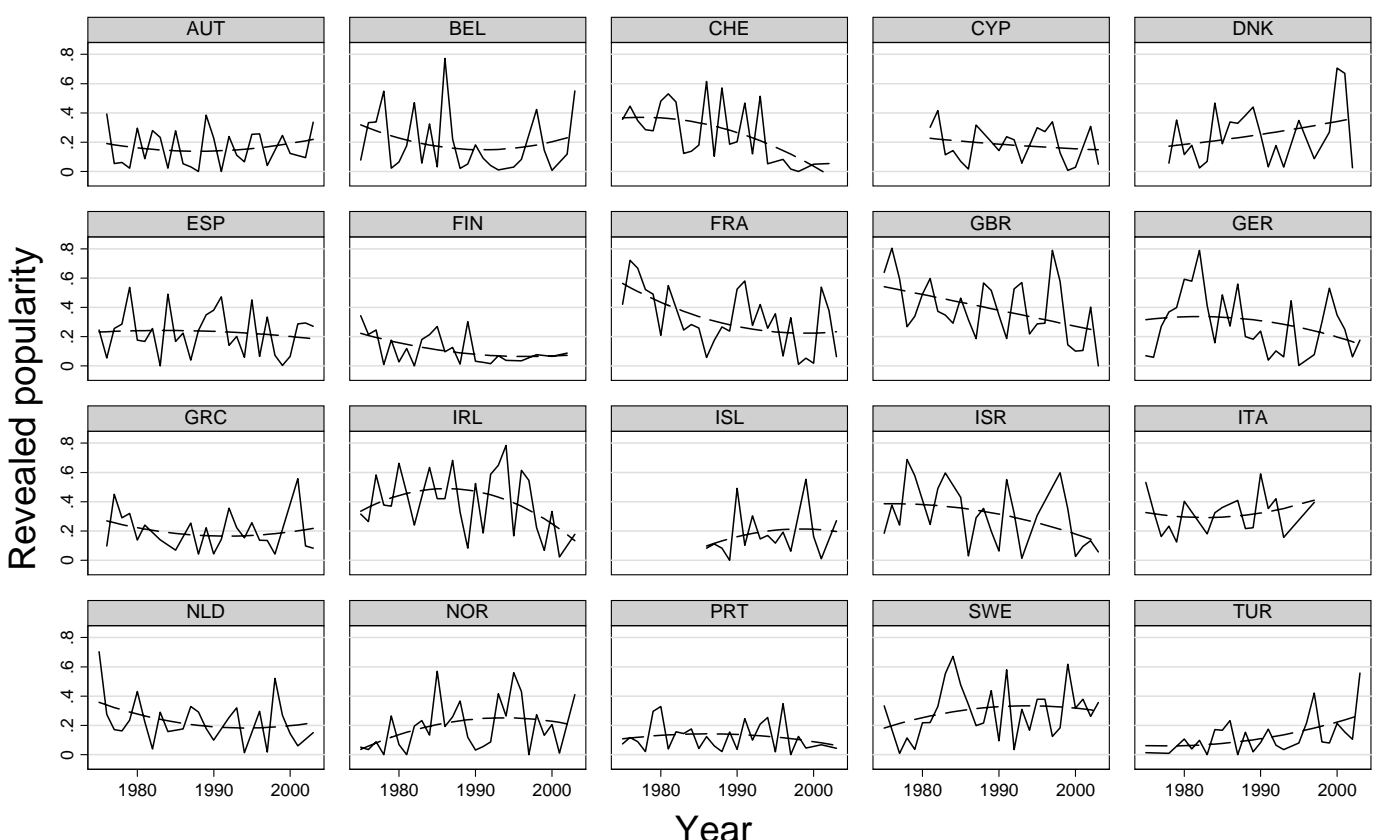

Fig. 1. Time profiles of multilateral scores obtained by countries. 
Table 1

Taking into account the change in ESC's rules

Televoting versus jury decision

\begin{tabular}{|c|c|c|c|}
\hline \multirow[t]{2}{*}{ Variables } & \multirow{2}{*}{$\begin{array}{l}\text { Aggregate } \\
\text { Import }\end{array}$} & \multirow{2}{*}{$\begin{array}{l}\text { Differentiated } \\
\text { Goods }\end{array}$} & \multirow{2}{*}{$\begin{array}{r}\text { Homogeneous } \\
\text { Goods }\end{array}$} \\
\hline & & & \\
\hline \multirow[t]{2}{*}{$E S C_{i j t}$} & $0.116^{* *}$ & $0.120^{* *}$ & 0.134 \\
\hline & $(0.046)$ & $(0.051)$ & $(0.093)$ \\
\hline \multirow[t]{2}{*}{$E S C_{j i t}$} & 0.0507 & 0.0617 & -0.0319 \\
\hline & $(0.048)$ & $(0.052)$ & $(0.087)$ \\
\hline \multirow[t]{2}{*}{ Ln Distance } & $-0.599^{* * *}$ & $-0.479^{* * *}$ & $-0.855^{* * *}$ \\
\hline & $(0.073)$ & $(0.064)$ & $(0.13)$ \\
\hline \multirow[t]{2}{*}{ Adjacency } & -0.0706 & -0.0279 & $0.637^{* * *}$ \\
\hline & $(0.10)$ & $(0.12)$ & $(0.20)$ \\
\hline \multirow[t]{2}{*}{ Both country in same FTA } & 0.0170 & -0.0252 & $0.378^{* * *}$ \\
\hline & $(0.044)$ & $(0.047)$ & $(0.11)$ \\
\hline \multirow[t]{2}{*}{ Direct communication } & -0.621 & -0.104 & -0.263 \\
\hline & $(0.55)$ & $(0.27)$ & $(1.06)$ \\
\hline \multirow[t]{2}{*}{ Open-circuit communication } & $1.051^{* *}$ & $0.724^{* * *}$ & 0.963 \\
\hline & $(0.51)$ & $(0.24)$ & $(0.86)$ \\
\hline \multirow[t]{2}{*}{ Common legal origin } & $0.399^{* * *}$ & $0.393^{* * *}$ & $0.437^{* * *}$ \\
\hline & $(0.074)$ & $(0.072)$ & $(0.14)$ \\
\hline \multirow[t]{2}{*}{ Religious proximity } & 0.188 & $0.247^{* *}$ & 0.0632 \\
\hline & $(0.13)$ & $(0.13)$ & $(0.25)$ \\
\hline \multirow[t]{2}{*}{ Ethnic ties } & $0.227^{* * *}$ & $0.241^{* * *}$ & $0.0826^{*}$ \\
\hline & $(0.029)$ & $(0.027)$ & $(0.049)$ \\
\hline Observations & $7,6.98$ & 6,499 & 6,021 \\
\hline Adusted $R^{2}$ & 0.920 & 0.917 & 0.744 \\
\hline RMSE & 0.690 & 0.681 & 1.207 \\
\hline
\end{tabular}

All regressions contain dyadic (i.e. country-pair) fixed effects, as well as 
Table 2

Migration and ESC scores

Without the German-Turkish pair

\begin{tabular}{|c|c|c|c|}
\hline \multirow[t]{2}{*}{ Variables } & \multirow{2}{*}{$\begin{array}{l}\text { Aggregate } \\
\text { Import }\end{array}$} & \multirow{2}{*}{$\begin{array}{l}\text { Differentiated } \\
\text { Goods }\end{array}$} & \multirow{2}{*}{$\begin{array}{r}\text { Homogeneous } \\
\text { Goods }\end{array}$} \\
\hline & & & \\
\hline \multirow[t]{2}{*}{$E S C_{i j t}$} & $0.140^{* * *}$ & $0.148^{* * *}$ & 0.0885 \\
\hline & $(0.043)$ & $(0.049)$ & $(0.085)$ \\
\hline \multirow[t]{2}{*}{$E S C_{j i t}$} & 0.0551 & $0.0904^{*}$ & 0.00811 \\
\hline & $(0.047)$ & $(0.052)$ & $(0.084)$ \\
\hline \multirow[t]{2}{*}{ Ln Distance } & $-0.780^{* * *}$ & $-0.584^{* * *}$ & $-0.872^{* * *}$ \\
\hline & $(0.068)$ & $(0.064)$ & $(0.14)$ \\
\hline \multirow[t]{2}{*}{ Adjacency } & -0.109 & 0.0217 & $0.720^{* * *}$ \\
\hline & $(0.10)$ & $(0.12)$ & $(0.20)$ \\
\hline \multirow[t]{2}{*}{ Both country in same FTA } & 0.00115 & -0.0392 & $0.379^{* * *}$ \\
\hline & $(0.045)$ & $(0.045)$ & $(0.11)$ \\
\hline \multirow[t]{2}{*}{ Direct communication } & -0.503 & -0.112 & -0.384 \\
\hline & $(0.46)$ & $(0.28)$ & $(0.99)$ \\
\hline \multirow[t]{2}{*}{ Open-circuit communication } & $1.093^{* *}$ & $0.665^{* * *}$ & 0.903 \\
\hline & $(0.46)$ & $(0.25)$ & $(0.80)$ \\
\hline \multirow[t]{2}{*}{ Common legal origin } & $0.368^{* * *}$ & $0.384^{* * *}$ & $0.331^{* *}$ \\
\hline & $(0.065)$ & $(0.068)$ & $(0.14)$ \\
\hline \multirow[t]{2}{*}{ Religious proximity } & 0.114 & $0.275^{* *}$ & 0.118 \\
\hline & $(0.12)$ & $(0.12)$ & $(0.24)$ \\
\hline \multirow[t]{2}{*}{ Ethnic ties } & $0.228^{* * *}$ & $0.219^{* * *}$ & $0.107^{* *}$ \\
\hline & $(0.025)$ & $(0.026)$ & $(0.045)$ \\
\hline Observations & 9,618 & 7,286 & 6,651 \\
\hline Adusted $R^{2}$ & 0.917 & 0.913 & 0.748 \\
\hline RMSE & 0.723 & 0.699 & 1.204 \\
\hline
\end{tabular}

All regressions contain dyadic (i.e. country-pair) fixed effects, as well as 